\title{
STUDIES IN FOSSIL BOTANY
}

An Introduction to the Study of Fossil Plants By Prof. John Walton. Pp. $x+188$. (London : Adam and Charles Black, Ltd., 1940.) 15s. net.

7 HIS book, intended for those who have had at least a year's university or college course in botany, will be welcomed not only by university students but also by those select readers who desire a brief, well-balanced account of the fascinating succession of floras that have clothed the earth. The value of the descriptive matter, which is clear and concise, is enhanced by the illustrations, which are generous in number and well chosen. The probable relationships between the living and the fossil representatives of the various groups of plants are adequately indicated, while fruitless speculation on the more problematical affinities has been avoided. D. H. Scott's "Studies in Fossil Botany" being now out of print, the book under review replaces it in the publisher's lists.

In his preface, the author expresses the hope that his readers will make a point of examining the actual specimens of fossil plants which are preserved in university and museum collections, and that they will institute active searches for fossils in such likely places as quarries and the spoil-heaps of collieries : such a course will indeed amply repay, in increasing understanding and zest, the trouble involved. Even the novice may hope to have the good fortune to find specimens which are worthy to be added to the priceless collections in our museums, and may also find hitherto unknown localities for fossils which may possibly yield a rich harvest of new forms.

The first chapter of the book classifies plant remains in general into compressions, incrustations, casts and petrifactions, and gives an excellent account of the many methods employed in investigating the specimens in the laboratory. Great advances have been made in a number of these methods in recent years, and Prof. Walton has been in the forefront of those who have made them; one of the most remarkable results of micro-palæobotanical research was his discovery of the oldest known (Carboniferous) liverworts (p. 22).

The body of the work deals with the chief groups of plants in the order of increasing complexity, each group being illustrated by a number of types. In the account of the Thallophyta it is shown that the recognition of fossil bacteria depends less on their external form than on the traces of their physiological activity. This would have been an appropriate place for a brief reference to the role of anaerobic bacteria in coal-formation and for mention of the recent work of Lipman, Farrell and Turner on the bacteria occurring in coal. On the other hand, the description of Pachytheca might well have been omitted, since its vegetable nature is open to doubt. The description of the early vascular plants is a particularly good review of exceptionally difficult material.

A reference to the spores which occur abundantly in most coal-seams is made in the account of the Lycopodiales, plants which disseminated spores in countless numbers. The preparation of graphs summarizing the vertical distribution of arbitrarily chosen spore-types in coal-seams has recently been pressed into service in the difficult task of endeavouring to correlate the seams. This method is, however, still in its early stages. While it may be doubted whether sufficient evidence has yet been adduced to warrant the statement (p. 57) that "a similar graph is usually obtained if the same seam is analysed in a different part of the coal-field", it is certainly not necessarily true that "a different seam will show quite a distinct form of graph".

The final chapter of the book, on the succession of the floras and climates, is full of interesting matter. The climate of Europe and North America during Upper Carboniferous times is described as "probably warm" (p. 135) and as "between temperate and tropical" (p. 174), but the plant evidence on this point may be regarded as less conclusive than even these statements imply. Furthermore, studies on certain other forms of contemporary life and on certain sediments have led to conclusions which are actually contradictory. Despite the uncertainty, as Prof. Walton points out, we have considerable evidence, important to the botanist, as to the ecological conditions under which the plants lived.

The text is completed by a representative bibliography and a useful index; the outline classifications given at the beginning of most of the chapters, and the several tables included in the text, are valuable guides to the complex botanical and geological divisions. This book is a stimulating account of the subject and admirably fulfils its purpose. Both the author and the publishers are to be congratulated on the production.
R. Crookall. 